\title{
Comparison of Lidocaine Spray and Lidocaine Ice Popsicle in Patients Undergoing Unsedated Esophagogastroduodenoscopy: A Single Center Prospective Randomized Controlled Trial
}

\author{
Prasit Mahawongkajit (iD) \\ Nantawat Talalak' \\ Neranchala Soonthornkes ${ }^{2}$ \\ 'Department of Surgery, Faculty of \\ Medicine, Thammasat University, \\ Pathumthani, I2120, Thailand; \\ ${ }^{2}$ Department of Anesthesiology, Faculty \\ of Medicine, Thammasat University, \\ Pathumthani, 12120, Thailand
}

\begin{abstract}
Purpose: Esophagogastroduodenoscopy (EGD) under topical pharyngeal anesthesia has the advantage of avoiding the unwanted cardiopulmonary adverse events experienced following intravenous sedation. Lidocaine spray is a common anesthetic option and is safe for unsedated EGD. Although several studies have compared different topical anesthetic agents, their formulations, and delivery techniques, questions still remain concerning the optimal mode of administration. We have designed a lidocaine formulation in the form of an ice popsicle and compared its effectiveness and tolerability with lidocaine spray in patients undergoing unsedated EGD.
\end{abstract}

Methods: This was a single-center prospective randomized controlled trial. Unsedated EGD patients were randomly allocated the lidocaine spray [Group (Gp) A] or lidocaine ice popsicle ( $\mathrm{Gp} \mathrm{B}$ ) formulation.

Results: In total, 204 unsedated EGD patients were evaluated. Compared to the spray, the lidocaine ice popsicle group showed better scores for effects in terms of endoscopist satisfaction (Gp A, 7.28 \pm 1.44 ; Gp B, 7.8 \pm 0.89 ; p=0.0022), gag reflex (Gp A, 1.3 \pm 0.66 ; Gp B, $1.02 \pm 0.61$; $\mathrm{p}=0.0016$ ), patient satisfaction ( $\mathrm{Gp} \mathrm{A}, 7.74 \pm 0.82 ; \mathrm{Gp} \mathrm{B}, 8.08 \pm 0.82 ; \mathrm{p}=0.0039$ ), discomfort (Gp A, $6.54 \pm 1.34 ; \mathrm{Gp} \mathrm{B}, 5.95 \pm 1.21 ; \mathrm{p}=0.0012$ ), and pain (Gp A, 5.38 $\pm 1.85 ; \mathrm{Gp} \mathrm{B}, 4.51 \pm 2.01 ; \mathrm{p}=0.0015$ ).

Conclusion: Both the lidocaine spray and ice popsicle formulations are safe, effective options for diagnostic EGD with the ice popsicle exhibiting better performance. We propose the lidocaine ice popsicle formulation for topical pharyngeal anesthesia in patients undergoing unsedated diagnostic EGD and suggest it may be a suitable option during the COVID-19 pandemic.

Clinical Trial Register: Thai Clinical Trials Registry (TCTR) number TCTR20190502001. Keywords: lidocaine spray, lidocaine ice popsicle, esophagogastroduodenoscopy, upper gastrointestinal endoscopy, topical pharyngeal anesthesia

\section{Introduction}

Esophagogastroduodenoscopy (EGD) is an essential and widely used diagnostic and therapeutic procedure in gastroenterology. ${ }^{1-4}$ EGD can be performed in association with topical anesthesia of the pharynx, ${ }^{5,6}$ intravenous anesthesia, ${ }^{7-9}$ or with their combination. ${ }^{10-13}$ EGD under topical pharyngeal anesthesia has the advantage of avoiding unwanted cardiopulmonary adverse events from intravenous sedationlike respiratory depression, cardiorespiratory arrest, especially in patients with cardiopulmonary disease, the elderly, and obese. ${ }^{14-16}$
Correspondence: Prasit Mahawongkajit Department of Surgery, Faculty of Medicine, Thammasat University (Rangsit Campus), 99/209 Moo 18, Paholyothin Road, Amphur Klongluang, Pathumthani, 12120, Thailand

Tel +6629269523

Fax +6629269530

Email prasit_md@yahoo.com 
In Thailand, lidocaine spray is commonly used and is safe and easy in procedures requiring unsedated EGD. Many studies have compared topical anesthetic agents to other formulations and techniques such as viscous, lozenge, lollipop, and nebulized lidocaine administration. However, it is still unclear which technique is optimal in terms of its influence on the gag reflex, patient tolerability, and pain. ${ }^{17-22}$ A recent study demonstrated the effectiveness of using ice for topical anesthesia of the oral mucosa compared to lidocaine $5 \%$ gel dental injection. ${ }^{23}$ The ice popsicle is a famous dessert in Thailand due to the hot weather and led us to the idea of using this for delivering lidocaine. We, therefore, designed the present study to develop and compare the lidocaine ice popsicle and lidocaine spray in patients undergoing unsedated EGD.

\section{Materials and Methods}

This study was a single-center, prospective randomized, controlled trial that was registered with the Thai Clinical Trials Registry (TCTR20190502001) (Date of registration 02/05/2019). This study was approved by the Human Ethics Committee of Thammasat University (Faculty of Medicine), reference number MTU-EC-SU-1-253/61.

From May 2019 to January 2020 and May to August 2020, we enrolled consecutive patients with a minimum age of 20 years, eligible for unsedated diagnostic EGD via the oral route by pharyngeal anesthesia at Thammasat University Hospital. The indications of diagnostic endoscopy were cancer screening and work-up for symptomatic patients such as dysphagia, dyspepsia, reflux, abdominal pain, or anemia. Patients with head and neck cancer, upper gastrointestinal cancer, previous surgery of the upper aerodigestive tract, corrosive ingestion, pregnancy, contraindication for EGD, allergy to lidocaine, psychiatric problems, neuromuscular disorders, emergency cases, and unstable vital signs were excluded from the study. All patients were fully informed of the objectives of this study. All procedures were performed in accordance with the declaration of Helsinki. Written informed consent was obtained from each patient before randomization.

The patients were randomly allocated by a research assistant to one of two groups using the opaque sealed envelope technique: (i) lidocaine spray [Group (Gp) A] or (ii) lidocaine popsicle (Gp B). The lidocaine spray was applied as two puffs to the left side, right side, and middle part of the pharynx (10 mg lidocaine/metered dose) and then repeated five minutes apart for a total of $120 \mathrm{mg}$ of lidocaine. The lidocaine ice popsicle consisting of a $6 \mathrm{~mL}$ of a viscous lidocaine solution $(20 \mathrm{mg} / \mathrm{mL})$ was formed on a silicone mold with a stick inserted in the center. The preparation was stored overnight in a freezer until the day of the endoscopy. The ice popsicle (Figure 1) contained $120 \mathrm{mg}$ of lidocaine and was required to be sucked by the patient until it completely dissolved, which usually required approximately five minutes.

Anxiety was evaluated using a numerical rating scale (NRS) before applying the topical pharyngeal anesthesia (range 0 , calm to 10 , anxious). Topical pharyngeal anesthesia was applied by the first endoscopy nurse. After 2 to 5 minutes, the EGD was performed by a single operator, having experience with $>1000$ EGDs, accompanied by a second endoscopy nurse (a registered nurse skilled in assisting endoscopists performing endoscopies). The endoscopist and second endoscopy nurse were blinded to the lidocaine allocation group. All EGDs were performed using one of two models of standard upper endoscopes (GIF-HQ190 and GIF-H290Z; Olympus, Tokyo, Japan).

After completing the endoscopic examination, the research assistant administered a questionnaire. Different NRSs were used to assess: procedural experience $(0$, no discomfort and 10, the worst discomfort imaginable), pain score ( 0 , no pain and 10 , pain as bad as it could be), and patient satisfaction ( 0 , no satisfaction and 10 , extreme satisfaction). In addition, the ease of use of esophageal instrumentation ( 0 , very difficult and 10 , very easy), satisfaction ( 0 , no satisfaction and 10 , extreme satisfaction), and the gag reflex ( 0 , no gag reflex; 1 , mild gag reflex; 2 , moderate gag reflex sedation not needed; 3 , strong gag

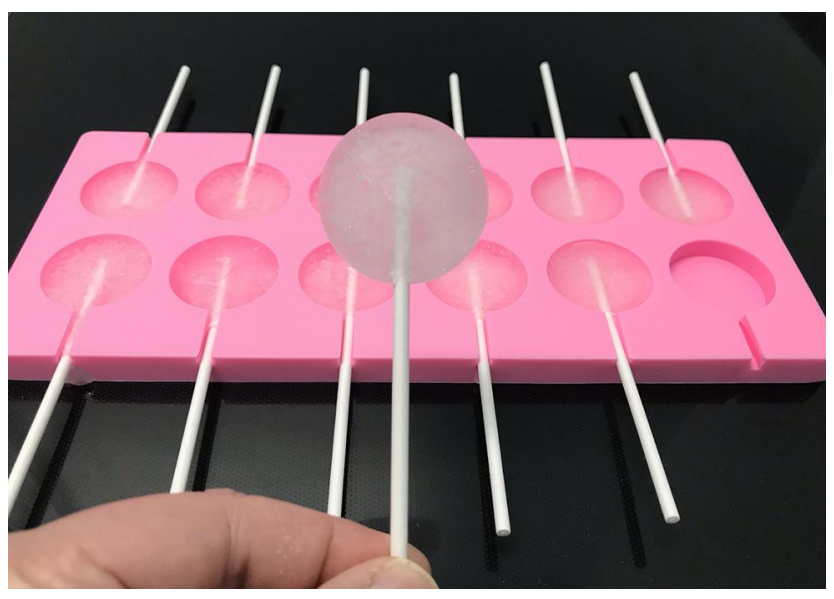

Figure I Lidocaine ice popsicle. The lidocaine ice popsicle made by viscous lidocaine solution $20 \mathrm{mg} / \mathrm{mL}, 6 \mathrm{~mL}$ with a stick in the silicone mold. It is stored overnight in the freezer to the day of endoscopy. 
reflex sedation needed; 4, strong gag reflex and instrumentation refused). The following data was inserted on the case record forms: patient characteristics, endoscopic examination, and duration. All patient data were analyzed in a blind manner.

Several studies have demonstrated that lidocaine spray is superior to other anesthetic formulations. ${ }^{17-19,22} \mathrm{We}$ chose to include the endoscopists' satisfaction as a parameter because the study design included an endoscopic procedure performed by a single blinded operator with an overview of the overall procedure, which was evaluated using NRS. A prior study evaluated the endoscopist's satisfaction using a visual analog scale (VAS: 0 (very unsatisfied) to 10). The VAS for the lidocaine spray group $(7.54 \pm 1.97)$ was higher than that the lozenge formulation group $(6.87 \pm 2.35) .{ }^{19}$ We estimated that the sample size needed for a two-sample comparison of means
(STATA/SE 12.0 for MAC, StataCorp LP, Texas, USA) under the research hypothesis to determine the superiority of the novel formulation of anesthetic agents required a total of 214 interventions for an alpha error 0.05 and beta-error 0.20 (Power $80 \%$ ) with a ratio of sample size of 1. Thus, a sample size of 107 was needed for each group. The primary outcome was to evaluate the difference in the endoscopists' satisfaction between two groups. The secondary outcome was esophageal endoscopy instruments, gag reflex, patients' satisfaction, anxiety, pain, discomfort, adverse events, need for sedation, procedural duration, and complete endoscopy.

The data are expressed as mean \pm standard error of the mean. Statistical analysis was performed using the $\chi^{2}$ test and Fisher's test for categorical data and the MannWhitney $U$-test was used for continuous data. All data were analyzed with SPSS v.22.0 data (Statistical Package

\section{CONSORT 2010 Flow Diagram}

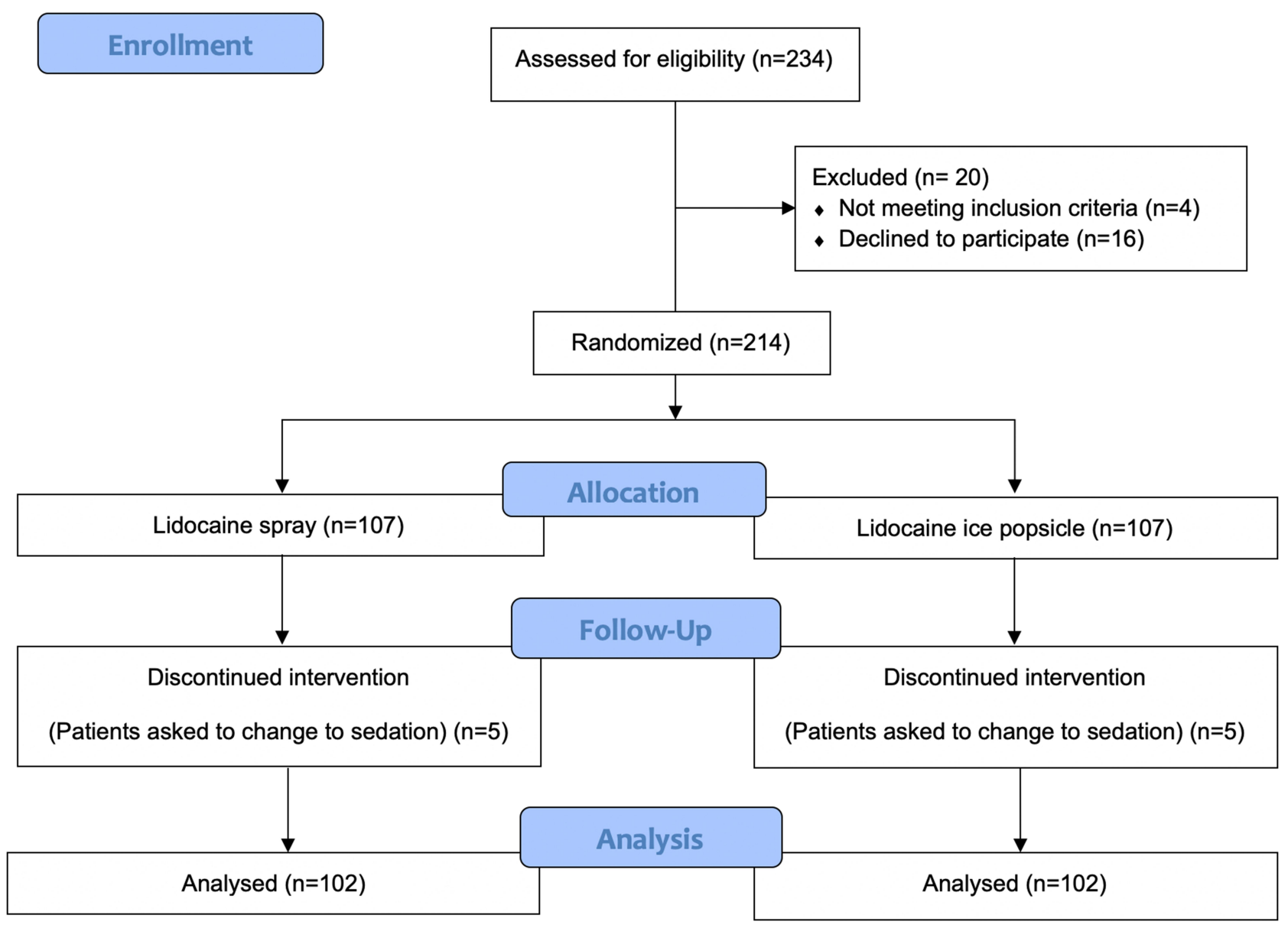

Figure 2 CONSORT flow diagram. 
for Social Sciences, SPSS, Inc., Chicago, IL, USA). A p-value $<0.05$ was considered to be statistically significant.

\section{Results}

A total of 234 patients were evaluated for study inclusion. Four were excluded because of one case of previous oropharyngeal surgery, one case of nasopharyngeal cancer with post-radiation treatment, and two cases with a history of corrosive ingestion. Sixteen patients declined to provide informed consent. Next, 214 patients were randomized; 107 in each group. After randomization, 5 patients in each group discontinued the study because they asked to change to the type of sedation. Finally, a total of 204 patients were analyzed (Figure 2).

The two groups were not significantly different $(\mathrm{p}>$ 0.05) in terms of age, sex, BMI, smoking, alcohol intake, and prior endoscopy (Table 1). The main clinical for EGD was dyspepsia.

Pre-endoscopic anxiety was not significantly different between the groups. The participants' procedural evaluation results demonstrated lower NRS scores for discomfort and pain with higher patient satisfaction in the lidocaine ice popsicle preparation group (Table 2). There was also a significantly higher NRS score for the lidocaine ice popsicle preparation in terms of endoscopist satisfaction and also a significantly lower gag reflex score. The mean times to perform the EGD and EGD accompanied by biopsy were very similar in both groups. Intraendoscopic oxygen desaturation was identified in patients in Gp A and in one patient in Gp B, but this difference was not statistically significant. No patient suffered bradycardia or hypotension. Only two participants who had received the lidocaine spray could not tolerate the procedure and proceeded to the intervention with sedation.

\section{Discussion}

EGD is an established technique for investigating disorders of the gastrointestinal tract. Endoscopes must be inserted through the mouth and this leads to patient anxiety, discomfort, coughing, and gagging, which may make the experience all together unpleasant. 5,6,11-13,17-25 Intravenous anesthesia is an option for EGD but holds the risk of adverse events such as bradycardia, hypotension, and respiratory depression, particularly when administered by non-anesthetists. ${ }^{26,27,30-33}$ The use of topical pharyngeal anesthesia reduced the use and risk of intravenous sedation and directed researcher's attention towards alleviating the gag reflex, pain, discomfort, and improving tolerability of unsedated patients and towards studies to ascertain how to improve tolerability.

Many publications report the use of different local anesthetic preparations such as viscous lidocaine solution, ${ }^{17,18}$ lozenges, ${ }^{19,20}$ lollipops, $^{21}$ and nebulized

Table I Patient Characteristics of Each Group

\begin{tabular}{|c|c|c|c|}
\hline Unsedated EGD Patients & Group A: Lidocaine Spray n= 02 & Group B: Lidocaine Ice Popsicle n= 02 & p-value \\
\hline Age, mean $\pm S D$, years & $59.86 \pm 9.36$ & $57.75 \pm 13.43$ & 0.119 \\
\hline Sex Male/Female, n (\%) & $52(50.89) / 50(49.11)$ & $54(52.94) / 48(47.06)$ & $0.78 \mathrm{I}$ \\
\hline Body weight $(\mathrm{kg})$ & $61.87 \pm 2.12$ & $61.27 \pm 9.89$ & 0.742 \\
\hline Height (m) & $1.64 \pm 0.05$ & $1.65 \pm 0.07$ & 0.579 \\
\hline $\mathrm{BMI}^{\dagger}\left(\mathrm{kg} / \mathrm{m}^{2}\right)$ & $22.72 \pm 0.52$ & $22.13 \pm 3.43$ & 0.209 \\
\hline Current smoker, n (\%) & $18(17.65)$ & $22(21.57)$ & 0.483 \\
\hline Current alcohol drinker, n (\%) & $29(28.43)$ & $34(33.33)$ & 0.451 \\
\hline \multicolumn{4}{|l|}{ Indication for EGD } \\
\hline Cancer screening, n (\%) & $16(15.69)$ & $14(13.73)$ & 0.694 \\
\hline Reflux, n (\%) & $12(11.76)$ & $15(14.71)$ & 0.538 \\
\hline Dysphagia, n (\%) & $2(1.96)$ & $4(3.92)$ & 0.409 \\
\hline Dyspepsia, n (\%) & $38(37.26)$ & $36(35.29)$ & 0.772 \\
\hline Epigastrium pain, n (\%) & $12(11.76)$ & II (I0.78) & 0.826 \\
\hline Anemia, n (\%) & $9(8.82)$ & $12(11.77)$ & 0.492 \\
\hline Other, n (\%) & $13(12.75)$ & $10(9.8)$ & 0.509 \\
\hline Prior experience of EGD, $\mathrm{n}(\%)$ & $17(16.67)$ & $13(12.74)$ & 0.432 \\
\hline
\end{tabular}

Abbreviation: ${ }^{\dagger} \mathrm{BMI}$, body mass index. 
Table 2 Evaluation of Unsedated Upper Gastrointestinal Endoscopy

\begin{tabular}{|c|c|c|c|}
\hline & Group A: Lidocaine Spray & Group B: Lidocaine Ice Popsicle & p-value \\
\hline \multicolumn{4}{|l|}{ Endoscopist } \\
\hline Endoscopists' satisfaction, mean \pm SD, 0-10 NRS ${ }^{\dagger}$ & $7.28 \pm 1.44$ & $7.8 \pm 0.89$ & 0.0022 \\
\hline Easy esophageal instrumentation, mean $\pm \mathrm{SD}, 0-10 \mathrm{NRS}^{\dagger}$ & $7.49 \pm 0.92$ & $7.71 \pm 0.89$ & 0.089 \\
\hline Gag reflex, mean \pm SD, $0-4 \mathrm{NRS}^{\dagger}$ & $1.3 \pm 0.66$ & $1.02 \pm 0.61$ & 0.0016 \\
\hline \multicolumn{4}{|l|}{ Participants } \\
\hline Anxiety, mean $\pm \mathrm{SD}, 0-10 \mathrm{NRS}^{\dagger}$ & $6.34 \pm 2$ & $6.29 \pm 1.9$ & 0.868 \\
\hline Procedural discomfort, mean $\pm \mathrm{SD}, 0-10 \mathrm{NRS}^{\dagger}$ & $6.54 \pm 1.34$ & $5.95 \pm 1.21$ & 0.0012 \\
\hline Pain score, mean \pm SD, $0-10 \mathrm{NRS}^{\dagger}$ & $5.38 \pm 1.85$ & $4.51 \pm 2.01$ & 0.0015 \\
\hline Patients' satisfaction, mean \pm SD, 0-10 NRS ${ }^{\dagger}$ & $7.74 \pm 0.82$ & $8.08 \pm 0.82$ & 0.0039 \\
\hline \multicolumn{4}{|l|}{ Endoscopic outcome } \\
\hline Oxygen desaturation, $\mathrm{n}(\%)$ & $3(2.94)$ & $\mathrm{I}(0.98)$ & 0.315 \\
\hline Bradycardia, n (\%) & $0(0)$ & $0(0)$ & 0 \\
\hline Hypotension, n (\%) & $0(0)$ & $0(0)$ & 0 \\
\hline Procedural duration, mean $\pm S D$, minutes & $9.59 \pm 1.72$ & $9.44 \pm 0.71$ & 0.488 \\
\hline • Only EGD, n (\%) & $19(18.6)$ & $18(17.6)$ & 0.86 \\
\hline - Duration, mean $\pm S D$, minutes & $7.58 \pm 0.5$ & $7.83 \pm 0.51$ & 0.139 \\
\hline • EGD with biopsy, n (\%) & $83(81.4)$ & $84(82.4)$ & 0.86 \\
\hline - Duration, mean $\pm S D$, minutes & $10.05 \pm 1.56$ & $9.78 \pm 0.71$ & 0.212 \\
\hline Complete endoscopy, n (\%) & $102(100)$ & $102(100)$ & 0 \\
\hline Need for sedation, n (\%) & $2(1.96)$ & $0(0)$ & 0.157 \\
\hline
\end{tabular}

Abbreviation: ${ }^{\dagger} \mathrm{NRS}$, numerical rating scale.

lidocaine, ${ }^{22}$ but the efficacy and tolerability of these techniques are still under debate. We, therefore, developed the idea of a lidocaine popsicle preparation and reviewed lidocaine stability data under different freezing conditions. $^{28,29}$ We proposed that a lidocaine ice popsicle preparation as an unconventional preparation for an anesthetic agent that could reduce the stress of unsedated EGD patients during the $\sim 5$ minutes required for melting. Nonetheless, we found that the patients' pre-procedural anxiety scores were similar.

Compared to spray preparations, the lidocaine ice popsicle preparation was superior in terms of reducing the gag reflex, improving patient satisfaction, discomfort, and pain. The ice popsicle melted slowly and may have increased the exposure to lidocaine on the pharyngeal mucosa. To compensate for this potential advantage, we repeated the lidocaine spray after 5 minutes so that the total dose of lidocaine was the same for both groups. Ice popsicles are popular in Thailand because of the yearlong hot climate; thus, Thai people are accustomed to them and this may have had a positive collateral effect of increased relaxation prior to the insertion of the endoscope. Recent studies have demonstrated the efficacy of ice as an alternative to lidocaine $5 \%$ gel $^{23}$ and as a nonpharmacological intervention for pain management for dental procedures. ${ }^{34-38}$ Walco et al reported a 13-year-old leukemia patient who had difficulty swallowing pills was helped by using progressively larger pieces of ice, which helped to keep gagging and choking to a minimum, ${ }^{39}$ consistent with the concept of alternative adjunct therapies to improve the patient's comfort. ${ }^{40}$ The cold temperature might decrease neural transmission of stimuli in the thin unmyelinated neurons ${ }^{41,42}$ and local vasoconstriction may slow down lidocaine metabolism and absorption with a greater local anesthetic effect. ${ }^{43}$ The ice contact time of five minutes was safe and did not lead to tissue damage. ${ }^{43}$

The power calculation for study indicated a sample size of 214 patients was needed for this study. After randomized allocation 107 patients to each group, five patients asked the endoscopist to perform sedation before starting the endoscopic intubation in each group, a rate estimated to be $4.67 \%$, which demonstrated differences in the outcome. Further, two participants in the lidocaine spray group could not tolerate the endoscope and needed 
sedation, both had high anxiety scores. For a small number, neither procedural time nor satisfaction NRS $(1.96 \%$ in the lidocaine group) had been affected, with duration being 12 and 13 minutes, endoscopists' satisfaction NRS scored two and two, and patients' satisfaction NRS were five and five, respectively. The endoscopic examination of unsedated diagnostic EGD did not routinely involve oxygen supplementation at our endoscopy center. All patients were continuously and closely monitored for oxygen saturation and vital signs. Oxygen supplementation was given to the underlying disease patient when required. A total of four patients experienced oxygen desaturation during the EGD; two were aged 73 and 76, and two were obese by BMI 34.69 and 37.20, consistent with the published literature ${ }^{14-16}$ and our previous experience. Oxygen was administered via nasal cannula and the patients put in the left lateral position with satisfactory resolution.

The study was interrupted from January to May 2020 due to the COVID-19 pandemic in Thailand. The principal mode of transmission of coronavirus is airborne and contact ${ }^{44-46}$ and this had implications for performing EGDs. Droplets may be produced after spraying the lidocaine on the pharynx, ${ }^{47,48}$ although there is less of a concern with the lidocaine popsicle, which is probably a better option. The lidocaine ice popsicle can melt at room temperature after removal from the refrigerator, which would be fast in summer, especially in Thailand. The lidocaine ice popsicle needs to be stored in the freezer before use, which thus required the availability of a refrigerator as a potential limitation. Another limitation of this study was small number of participant numbers which limited our statistical power, although some findings were still significant. Some findings may have been due to chance, given the multiple comparisons.

\section{Conclusion}

We have shown that both lidocaine preparations were safe and effective in producing local anesthesia and were liked by patients, aside from the unpleasant taste. The lidocaine ice popsicle was associated with less discomfort, pain and gagging and was preferred by patients, which supported its higher satisfaction by patients. Additional larger studies are required to reconfirm our results and more work is needed to improve the taste of lidocaine.

\section{Abbreviations}

EGD, esophagogastroduodenoscopy; TCTR, Thai Clinical Trials Registry; BMI,body mass index; NRS, numerical rating scale.

\section{Data Sharing Statement}

The datasets used and/or analyzed during the present study are available from the corresponding author on reasonable request.

\section{Acknowledgments}

We thank the patients for participating in this research. Special thanks to Dr. Bob Taylor for assisting in editing the English version of this manuscript and Dr. Saritphat Orrapin for scrutinizing methodology and for statistical consultation. Special thanks to Supaporn Roipia, Nawapat Tipkongka, Wasana Khantasak, Supattra Thongon, and Somkid Dangduang for lidocaine ice popsicles preparation.

\section{Author Contributions}

All authors contributed to data analysis, drafting, and revising the article, have agreed on the journal to which the article will be submitted, gave final approval of the version to be published, and agree to be accountable for all aspects of the work.

\section{Funding}

This research supported in part by Thammasat University.

\section{Disclosure}

The authors report no conflicts of interest or financial ties to disclose.

\section{References}

1. Januszewicz W, Kaminski MF. Quality indicators in diagnostic upper gastrointestinal endoscopy. Therap Adv Gastroenterol. 2020;13:1756284820916693. doi:10.1177/1756284820916693

2. Yamamoto Y, Yahagi N, Yamamoto H, Ono H, Inoue H. Innovative therapeutic endoscopy in the upper gastrointestinal tract: a review of the JGES core sessions. Dig Endosc. 2020;32:882-887. doi:10.1111/ den. 13722

3. Emura F, Sharma P, Arantes V, et al. Principles and practice to facilitate complete photodocumentation of the upper gastrointestinal tract: World Endoscopy Organization position statement. Dig Endosc. 2020;32(2):168-179. doi:10.1111/den.13530

4. Chang KJ. Endoscopic foregut surgery and interventions: the future is now. The state-of-the-art and my personal journey. World J Gastroenterol. 2019;25(1):1-41. doi:10.3748/wjg.v25.i1.1

5. Carey EJ, Sorbi D. Unsedated endoscopy. Gastrointest Endosc Clin N Am. 2004;14(2):369-383. doi:10.1016/j.giec.2004.01.003

6. Sorbi D, Chak A. Unsedated EGD. Gastrointest Endosc. 2003;58 (1):102-110. doi:10.1067/mge.2003.309

7. Triantafillidis JK, Merikas E, Nikolakis D, Papalois AE. Sedation in gastrointestinal endoscopy: current issues. World $J$ Gastroenterol. 2013;19(4):463-481. doi:10.3748/wjg.v19.i4.463

8. Amornyotin S, Lertakayamanee N, Wongyingsinn M, Pimukmanuskit $\mathrm{P}$, Chalayonnavin V. The effectiveness of intravenous sedation in diagnostic upper gastrointestinal endoscopy. J Med Assoc Thai. 2007;90(2):301-306. 
9. Sidhu R, Turnbull D, Newton M, et al. Deep sedation and anaesthesia in complex gastrointestinal endoscopy: a joint position statement endorsed by the British Society of Gastroenterology (BSG), Joint Advisory Group (JAG) and Royal College of Anaesthetists (RCoA) Frontline Gastroenterol. 2019;10(2):141-147. doi:10.1136/flgastro2018-101145

10. Shah B, Cohen LB. The changing faces of endoscopic sedation. Expert Rev Gastroenterol Hepatol. 2010;4(4):417-422. doi:10.1586/ egh. 10.43

11. Heuss LT, Hanhart A, Dell-Kuster S, et al. Propofol sedation alone or in combination with pharyngeal lidocaine anesthesia for routine upper GI endoscopy: a randomized, double-blind, placebo-controlled, non-inferiority trial. Gastrointest Endosc. 2011;74(6):1207-1214. doi:10.1016/j.gie.2011.07.072

12. de la Morena F, Santander C, Esteban C, et al. Usefulness of applying lidocaine in esophagogastroduodenoscopy performed under sedation with propofol. World J Gastrointest Endosc. 2013;5(5):231-239. doi:10.4253/wjge.v5.i5.231

13. Ullman DA, Saleem SA, Shahnawaz A, Kotakanda S, Scribani MB, Victory JM. Relation of viscous lidocaine combined with propofol deep sedation during elective upper gastrointestinal endoscopy to discharge. Proc (Bayl Univ Med Cent). 2019;32(4):505-509. doi:10.1080/08998280.2019.1641058

14. Kollmann CM, Schmiegel W, Brechmann T. Gastrointestinal endoscopy under sedation is associated with pneumonia in older inpatients-results of a retrospective case-control study. United Eur Gastroenterol J. 2018;6(3):382-390. doi:10.1177/ 2050640617735059

15. Jirapinyo P, Thompson CC. Sedation challenges: obesity and sleep apnea. Gastrointest Endosc Clin N Am. 2016;26(3):527-537. doi:10.1016/j.giec.2016.03.001

16. Sharma VK, Nguyen CC, Crowell MD, Lieberman DA, de Garmo P, Fleischer DE. A national study of cardiopulmonary unplanned events after GI endoscopy. Gastrointest Endosc. 2007;66(1):27-34. doi:10.1016/j.gie.2006.12.040

17. Amornyotin S, Srikureja W, Chalayonnavin W, Kongphlay S, Chatchawankitkul S. Topical viscous lidocaine solution versus lidocaine spray for pharyngeal anesthesia in unsedated esophagogastroduodenoscopy. Endoscopy. 2009;41(7):581-586. doi:10.1055/s-0029-1214865

18. Khodadoostan M, Sadeghian S, Safaei A, Shavakhi AR, Shavakhi A. Viscous lidocaine solution versus lidocaine spray for pharyngeal local anesthesia in upper gastroesophageal endoscopy. J Res Med Sci. 2018;23:102. doi:10.4103/jrms.JRMS_579_17

19. Chan CK, Fok KL, Poon CM. Flavored anesthetic lozenge versus Xylocaine spray used as topical pharyngeal anesthesia for unsedated esophagogastroduodenoscopy: a randomized placebo-controlled trial. Surg Endosc. 2010;24(4):897-901. doi:10.1007/s00464-009-0687-9

20. Salale N, Treldal C, Mogensen S, et al. Bupivacaine lozenge compared with lidocaine spray as topical pharyngeal anesthetic before unsedated upper gastrointestinal endoscopy: a randomized, controlled trial. Clin Med Insights Gastroenterol. 2014;7:55-59. doi:10.4137/ CGast.S18019

21. Ayoub C, Skoury A, Abdul-Baki H, Nasr V, Soweid A. Lidocaine lollipop as single-agent anesthesia in upper GI endoscopy. Gastrointest Endosc. 2007;66(4):786-793. doi:10.1016/j. gie.2007.03.1086

22. Noitasaeng P, Vichitvejpaisal P, Kaosombatwattana U, Tassanee J, Suwannee S. Comparison of spraying and nebulized lidocaine in patients undergoing esophago-gastro-duodenoscopy: a randomized trial. J Med Assoc Thai. 2016;99(5):462-468.

23. Hindocha N, Manhem F, Bäckryd E, Bågesund M. Ice versus lidocaine $5 \%$ gel for topical anaesthesia of oral mucosa - a randomized cross-over study. BMC Anesthesiol. 2019;19(1):227. doi:10.1186/ s12871-019-0902-8
24. Jones MP, Ebert CC, Sloan T, et al. Patient anxiety and elective gastrointestinal endoscopy. J Clin Gastroenterol. 2004;38(1):35-40. doi:10.1097/00004836-200401000-00009

25. Mitsonis C, Dimopoulos N, Zavrou M, et al. Panic attack during elective gastrointestinal endoscopy. Gastroenterol Res Pract. 2011;2011:162574. doi:10.1155/2011/162574

26. Lin OS. Sedation for routine gastrointestinal endoscopic procedures: a review on efficacy, safety, efficiency, cost and satisfaction. Intest Res. 2017;15(4):456-466. doi:10.5217/ir.2017.15.4.456

27. Goudra BG, Singh PM, Gouda G, et al. Safety of non-anesthesia provider-administered propofol (NAAP) sedation in advanced gastrointestinal endoscopic procedures: comparative meta-analysis of pooled results. Dig Dis Sci. 2015;60(9):2612-2627. doi:10.1007/ s10620-015-3608-x

28. Larson PO, Ragi G, Swandby M, Darcey B, Polzin G, Carey P. Stability of buffered lidocaine and epinephrine used for local anesthesia. J Dermatol Surg Oncol. 1991;17(5):411-414. doi:10.1111/j.1524-4725.1991.tb03975.x

29. Donnelly RF. Stability of buffered lidocaine in glass vials. Can J Hosp Pharm. 2011;64(4):289-290. doi:10.4212/cjhp.v64i4.1059

30. Amornyotin S. Sedation-related complications in gastrointestinal endoscopy. World J Gastrointest Endosc. 2013;5(11):527-533. doi:10.4253/wjge.v5.i11.527

31. Repici A, Hassan C. The endoscopist, the anesthesiologists, and safety in GI endoscopy. Gastrointest Endosc. 2017;85(1):109-111. doi:10.1016/j.gie.2016.06.025

32. Delgado AAA, de Moura DTH, Ribeiro IB, et al. Propofol vs traditional sedatives for sedation in endoscopy: a systematic review and meta-analysis. World J Gastrointest Endosc. 2019;11(12):573-588. doi:10.4253/wjge.v11.i12.573

33. Guacho JAL, de Moura DTH, Ribeiro IB, et al. Propofol vs midazolam sedation for elective endoscopy in patients with cirrhosis: a systematic review and meta-analysis of randomized controlled trials. World J Gastrointest Endosc. 2020;12(8):241-255. doi:10.4253/wjge.v12.i8.241

34. Aminabadi NA, Farahani RM. The effect of pre-cooling the injection site on pediatric pain perception during the administration of local anesthesia. J Contemp Dent Pract. 2009;10:43-50. doi:10.5005/jcdp10-3-43

35. Ghaderi F, Banakar S, Rostami S. Effect of pre-cooling injection site on pain perception in pediatric dentistry: "A randomized clinical trial”. Dent Res J (Isfahan). 2013;10:790-794.

36. Wiswall AT, Bowles WR, Lunos S, McClanahan SB, Harris S. Palatal anesthesia: comparison of four techniques for decreasing injection discomfort. Northwest Dent. 2014;93:25-29.

37. Brignardello-Petersen R. Cold treatment as an adjunct to inferior alveolar nerve block may reduce pain and anxiety in patients undergoing endodontic treatment in mandibular molars with symptomatic irreversible pulpitis. J Am Dent Assoc. 2019;150(6):e98. doi:10.1016/ j.adaj.2019.02.003

38. Davoudi A, Rismanchian M, Akhavan A, et al. A brief review on the efficacy of different possible and nonpharmacological techniques in eliminating discomfort of local anesthesia injection during dental procedures. Anesth Essays Res. 2016;10(1):13-16. doi:10.4103/ 0259-1162.167846

39. Walco GA. A behavioral treatment for difficulty in swallowing pills. $J$ Behav Ther Exp Psychiatry. 1986;17(2):127-128. doi:10.1016/ 0005-7916(86)90050-9

40. Moore M, Schuler M, Wilson S, et al. More than pills: alternative adjunct therapies to improve comfort in hospitalised patients. $B M J$ Open Qual. 2019;8(2):e000506. doi:10.1136/bmjoq-2018-000506

41. Perlman SL. Modern techniques of pain management. West J Med. 1988;148(1):54-61.

42. DeLeo JA. Basic science of pain. J Bone Joint Surg Am. 2006;88 (Suppl 2):58-62. doi:10.2106/JBJS.E.01286 
43. Long RR. Cold fiber heat sensitivity: dependency of "paradoxical" discharge on body temperature. Brain Res. 1973;63:389-392. doi:10.1016/0006-8993(73)90110-8

44. Li Q, Guan X, Wu P. Early transmission dynamics in Wuhan, China, of novel coronavirus-infected pneumonia. N Engl J Med. 2020; NEJMoa2001316.

45. Rothe C, Schunk M, Sothmann P. Transmission of 2019-nCoV infection from an asymptomatic contact in Germany. $N$ Engl J Med. 2020;382:NEJMc2001468. doi:10.1056/NEJMc2001468

46. World Health Organization. Novel Coronavirus (2019-nCoV) advice for the public; 2020. Available from: https://www.who.int/emergen cies/diseases/novel-coronavirus-2019/advice-for-public. Accessed May 20, 2021.
47. Chiu PWY, Ng SC, Inoue $\mathrm{H}$, et al. Practice of endoscopy during COVID-19 pandemic: position statements of the Asian Pacific Society for Digestive Endoscopy (APSDE-COVID statements). Gut. 2020;69(6):991-996. doi:10.1136/gutjnl-2020-321185

48. Irisawa A, Furuta T, Matsumoto T, et al. Gastrointestinal endoscopy in the era of the acute pandemic of coronavirus disease 2019: recommendations by Japan Gastroenterological Endoscopy Society (Issued on April 9th, 2020). Dig Endosc. 2020;32:648-650. doi:10.1111/ den. 13703

\section{Publish your work in this journal}

Clinical and Experimental Gastroenterology is an international, peerreviewed, open access, online journal publishing original research, reports, editorials, reviews and commentaries on all aspects of gastroenterology in the clinic and laboratory. This journal is indexed on American Chemical Society's Chemical Abstracts Service (CAS).
The manuscript management system is completely online and includes a very quick and fair peer-review system, which is all easy to use. Visit http://www.dovepress.com/testimonials.php to read real quotes from published authors. 